\title{
ANALISIS USAHA DAN STRATEGI PENGEMBANGAN PEMASARAN BOLU KEMOJO DI KELURAHAN TANGKERANG SELATAN KECAMATAN BUKIT RAYA KOTA PEKANBARU (STUDI KASUS PADA USAHA CIK PUAN)
}

\section{Business Analysis and Marketing Development Strategy of Kemojo Bolu in Tangkerang Selatan Village, Bukit Raya District, Pekanbaru City (Case Study on Cik Puan Business)}

\author{
Imelda Putryansyah, Darus \\ Fakultas Pertanian Universitas Islam Riau Pekanbaru \\ Email: imelda.putryansyah21@gmail.com \\ [Diterima: Maret 2021; Disetujui: April 2021]
}

\begin{abstract}
This study aims to analyze the characteristics of the entrepreneur and the business profile of the kemojo sponge, the procurement of raw materials and supporting materials, processing technology, costs, income, business efficiency and added value, and strategy for marketing development of the kemojo sponge marketing. The method used was the survey method. Respondents were collected 1 manager and 2 workers in Tangkerang Selatan Village, Bukit Raya District, Pekanbaru City. The data collected consistsed of primary data and secondary data and were analyzed using descriptive qualitative and quantitative. The results showed that the age of manager was 49 years, while the average age of the workers was 23 years old. The length of education of manager was 12 years, while the worker was 12 years on avera. The family member of the manager was 3 people with 13 years experience, while the worker has an average experience of 4.5 years. The business has been starting from 2007 and had a business license. The source of capital from the Bank loan with household scale and used worker as 2 people. The use of raw materials per process production was $5 \mathrm{~kg}$ of flour, $\mathrm{Rp}$. 198,575 of supporting materials with the simple technology. The total cost was Rp. 319,020, the gross income was Rp. 1,020,000 and net income of IDR 700,980 per production process on average. The added value obtained was IDR $149,500 / \mathrm{kg}$ with the RCR of 2.20. Based on the strategy of developing the kemojo sponge agro-industrial business, it is stated that this business is in quadrant I, so it can perform the SO strategy, including maintaining product quality to increase consumer satisfaction and maintaining affordable product prices by looking at market information.
\end{abstract}

Keywords: Business Analysis, Development Strategy, Bolu Kemojo

\begin{abstract}
ABSTRAK
Penelitian ini bertujuan untuk menganalisis karakteristik pengusaha dan profil usaha bolu kemojo, pengadaan bahan baku dan bahan penunjang, teknologi pengolahan, biaya, pendapatan, efisiensi usaha dan nilai tambah dan strategi pengembangan pemasaran bolu kemojo di Kelurahan Tangkerang Selatan Kecamatan Bukit Raya Kota Pekanbaru. Metode yang digunakan adalah survei. Responden ditetapkan secara sensus sebanyak 1 orang pengusaha dan 2 orang tenaga kerja usaha cik puan. Data terdiri dari data primer dan data sekunder dan dianalisis deskriptif kualitatif dan kuantitatif. Hasil penelitian menunjukkan bahwa rataan umur pengusaha bolu kemojo adalah 49 tahun, umur tenaga kerja 23 tahun, lama pendidikan 12 tahun, pendidikan tenaga kerja 12 tahun, tanggungan keluarga maanjer 3 orang, sedangkan tenaga kerja tidak memiliki tanggungan. Pengalaman berusaha 13 tahun dan tenaga kerja rata-rata 4,5 tahun. Usaha Cik Puan dimulai dari tahun 2007 hingga saat ini dan sudah memiiki surat izin berusaha, sumber modal dari Bank, skala usaha termasuk skala rumah tangga dengan menggunakan tenaga kerja 2 orang. Penggunaan bahan sebanyak $5 \mathrm{~kg}$ tepung terigu dan bahan penunjang sebanyak Rp 198.575 per proses produksi dan teknologi yang digunakan masih sederhana. Per proses produksinya menggunakan biaya sebesar Rp 319.020 dan memperoleh pendapatan kotor sebesar $\mathrm{Rp} 1.020 .000$, pendapatan bersih sebesar Rp 700.980, nilai tambah yang diperoleh sebesar Rp 149.500/kg, dan $R C R$ yang yang diperoleh sebesar 2,20. Berdasarkan strategi pengembangan usaha agroindutri bolu kemojo menyatakan bahwa usaha ini berada pada kuadran I
\end{abstract}


sehingga dapat menjalankan strategi SO, diantaranya mempertahankan kualitas produk untuk meningkatkan kepuasan konsumen dan mempertahankan harga produk yang tetap terjangkau dengan melihat informasi pasar.

Kata kunci: Analisis Usaha, Strategi Pengembangan, Bolu Kemojo

\section{PENDAHULUAN}

Sektor pertanian berperan penting dalam pembangunan ekonomi nasional. Peranan sektor pertanian dalam pembagunan ekonomi ini antara lain : (1) menyediakan bahan pangan, sandang dan papan untuk memenuhi kebutuhan penduduk, (2) menyediakan bahan baku dari produk pertanian guna memenuhi permintaan pasar dari kegiatan agroindustri, (3) menyediakan lapangan kerja yang berkaitan langsung dan tidak langsung dengan kegiatan pertanian, (4) tenaga kerja disektor pertanian dapat sebagai sumber modal yang dapat dialokasikan pada pembangunan pertanian dan non pertanian, (5) mengasilkan devisa negara yang diperoleh dari hasil ekspor produk pertanian dan olahannya (Yasin, 1996).

Agroindustri mampu meningkatkan pendapatan para pelaku agribisnis, mampu menyerap tenaga kerja, mampu meningkatkan perolehan devisa negara dan mampu mendorong munculnya industri lainnya. Dengan demikian berbagai upaya pengembangan agroindustri dilaksanakan dengan tujuan diantaranya: (a) menarik dan mendorong munculnya industri baru disektor pertanian, (b) menciptakan struktur perekonomian yang tangguh, (c) menciptakan nilai tambah, (d) menciptakan lapangan pekerjaan dan memperbaiki pembagian pendapatan (Soekartawi, 2001).

Kota Pekanbaru memiliki potensi yang cukup besar untuk berkembangnya industri kecil yang mempunyai peranan penting dalam perekonomian nasional. Industri kecil di Kecamatan Bukit Raya Kota Pekanbaru dari tahun 2013 sampai tahun 2017 jumlahnya berfluktuasi, dimana jumlah industri yang tertinggi di tahun 2013 sebanyak 11 unit, dan industri paling kecil terjadi di tahun 2016 dan 2017 sebanyak 5 unit.

Pada Kecamatan Bukit Raya kota Pekanbaru terdapat 6 (enam) Desa/Kelurahan antara lain: 1) Kelurahan Tangkerang Labuai, 2) Kelurahan Dirgantara, 3) Kelurahan Simpang Tiga, 4) Kelurahan Tebing Tinggi, 5) Kelurahan Tangkerang Selatan, dan 6) Kelurahan Tangkerang Utara. Pada Kelurahan Tangkerang Selatan Kecamatan Bukit Raya terdapat beberapa indutri kecil dan produknya antara lain: 1) Cuuk Catering memproduksi kue basah dan kue kering, 2) Hilayati Snack memproduksi kue bangkit dan lain-lain , 3) Mawar memproduksi roti manis dan tawar, 4) Violin Bakery memproduksi aneka roti, 5) Cik puan memproduksi bolu kemojo dan lain-lain.

Salah satu agroindustri yang memiliki peluang yang sangat baik dan menjanjikan untuk dikembangkan lebih lanjut yaitu agroindustri bolu kemojo yang bisa meningkatkan minat konsumen dan meningkatkan nilai tambah bagi pengusaha. Bolu Kemojo mempunyai rasa yang manis, bentuk yang unik, dan harga yang terjangkau. Salah satu usaha yang memproduksi bolu kemojo yaitu usaha Cik Puan. Usaha Cik Puan ini adalah usaha industri kecil yang sudah berproduksi kurang lebih 13 tahun yang dikelolah oleh Bapak Anto dan memperkerjakan sebanyak 2 orang tenaga kerja yang ada di Pekanbaru.

Usaha Cik Puan menciptakan inovasi yang berbeda dengan industri kecil lainnya seperti varian rasa, ada rasa pandan, rasa durian, dan tekstur kelembutan.Usaha Cik Puan tersebut memproduksi dan memasarkan sendiri produk olahannya dan dikemas menggunakan kotak yang sudah ada label/merek usaha, dengan jumlah yang sesuai dengan permintaan pembeli.Dengan hal tersebut, tentunya usaha Cik Puan lebih banyak mengeluarkan biaya pemasaran dibandingkan dengan industri kecil lainnya yang hanya menggunakan kotak biasa atau tidak ada merek.

Meskipun tergolong kedalam industri rumah tangga, masih terdapat beberapa masalah yang dihadapi oleh usaha Cik Puan ini, diantaranya: 1) penggunaan teknologi yang masih sederhana dalam pengolahan bolu kemojo sangat berpengaruh terhadap kualitas seperti bentuk, rasa dan tekstur yang akan dihasilkan, 2) pemasaran yang kurang optimal atau kurangnya minat konsumen yang berada di sekitar wilayah Pekanbaru akan bolu kemojo sedangkan memiliki nilai tinggi di luar wilayah Pekanbaru. Oleh karena itu, industri bolu kemojo Cik Puan cukup baik untuk dikem- 
bangkan lebih lanjut agar bisa memberi nilai tambah bagi pengusaha.

Penelitian ini bertujuan untuk mengetahui karakteristik pengusaha dan profil usaha, penggunaan bahan baku, bahan penunjang, teknologi pengolahan, biaya, pendapatan, efisiensi usaha dan nilai Tambah dan strategi pengembangan pemasaran bolu kemojo Cik Puan.

Penelitian ini diharapkan dapat mengetahui apakah usaha yang dijalankan menguntungkan atau tidak menguntungkan serta sebagai acuan untuk kemajuan usaha yang dilakukan, menjadi bahan atas dasar pemikiran dalam membuat kebijakan yang berhubungan dengan perkembangan industri dimasa yang akan datang dan menambah pengetahuan terkait dengan industri bolu kemojo dan pengetahuan yang dikaji.

\section{METODOLOGI PENELITIAN}

Metode yang digunakan dalam penelitian ini metode studi kasus yang dilakukan pada usaha Cik Puan di Kelurahan Tangkerang Selatan Kecamatan Bukit Raya Kota Pekanbaru.Pemilihan lokasiini berdasarkan atas pertimbangan usaha tersebut memproduksi makanan khas Melayu Riau terutama Bolu Kemojo yang telah berproduksi sejak tahun 2007 sampai saat ini.

Penelitian dilaksanakan selama 6 (enam) bulan yang dimulai dari bulan Mei 2020 sampai dengan bulan Oktober 2020 yang meliputi kegiatan penyusunan proposal, pengumpulan data di lapangan, tabulasi data, analisis data, dan penulisan laporan.

\section{Analisis Data}

Untuk menghitung besarnya biaya produksi dapat dihitung dengan rumus (Soekartawi, 2002):

$\mathrm{TC}=\mathrm{TFC}+\mathrm{TVC}$

Keterangan:

$$
\begin{aligned}
\mathrm{TC}= & \text { Total Cost } \text { (total biaya) } \\
\mathrm{TFC}= & \text { Total Fixed Cost (total biaya tetap) } \\
\mathrm{TVC}= & \text { Total Variabel Cost (total biaya } \\
& \text { variabel) }
\end{aligned}
$$

Untuk kebutuhan penelitian, maka rumus tersebut diinformasikan menjadi

$\mathrm{TC}=\left\{\left(\mathrm{X}_{1} \cdot \mathrm{PX}_{1}\right)+\left(\mathrm{X}_{2} \cdot \mathrm{PX}_{2}\right)+\left(\mathrm{X}_{3} \cdot \mathrm{PX}_{3}\right)\right\}+\mathrm{D} \ldots(2)$

Keterangan:

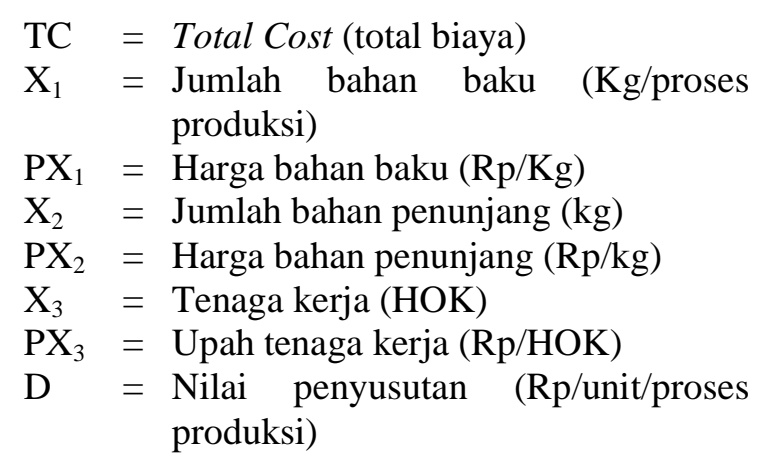

Untuk menghitung pendapatan kotor, yaitu (Hernanto, 2003)

$\mathrm{TR}=\mathrm{Y} . \mathrm{Py}$

Keterangan :

$\mathrm{TR}=$ Pendapatan kotor $(\mathrm{Rp} /$ proses produksi)

$\mathrm{Y}=$ Jumlah bolu kemojo (Rp/proses produksi)

Py $=$ Harga bolu kemojo $(\mathrm{Rp} / \mathrm{Kg})$

Untuk mengetahui pendapatan bersih dapat dihitung dengan menggunakan rumus umum menurut Soekartawi (2002), yaitu:

$\Pi=\mathrm{TR}-\mathrm{TC}$

Keterangan :

$\mathrm{TR}=$ Pendapatan kotor $(\mathrm{Rp} / \mathrm{proses}$ produksi $)$

$\mathrm{TC}=$ Total biaya $(\mathrm{Rp} /$ proses produksi)

$\pi=$ Pendapatan bersih pengusaha bolu kemojo (Rp/proses produksi)

Untuk mengetahui efisiensi menggunakan rumus menurut Soekartawi (1995) sebagai berikut:

$R C R=\frac{\mathrm{TR}}{\mathrm{TC}}$

Keterangan:

$\mathrm{RCR}=$ Ratio Biaya Dengan Penerimaan

$\mathrm{TR}=$ Pendapatan Kotor $(\mathrm{Rp} /$ proses produksi)

$\mathrm{TC}=$ Total Biaya $(\mathrm{Rp} / \mathrm{proses}$ produksi)

Dengan kriteria apabila:

RCR $>1=$ Usaha dikatakan efisien dan menguntungkan.

RCR $<1=$ Usaha dikatakan tidak efisien dan tidak menguntungkan.

$\mathrm{RCR}=1=$ Usaha dikatakan impas (tidak mengalami keuntungan maupun kerugian).

Untuk mengetahui nilai tambah produk agroindustri bolu kemojo dapat dianalisis dengan menggunakan metode hayami: 
Tabel 1. Variabel Perhitungan Nilai Tambah Metode Hayami

\begin{tabular}{cll}
\hline No & \multicolumn{1}{c}{ Variabel } & \multicolumn{1}{c}{ Nilai } \\
\hline 1 1) & Output, Input dan Harga & $(1)$ \\
\hline 1 & Output (Kg) & $(2)$ \\
2 & Input (Kg) & $(3)$ \\
3 & Tenaga Kerja Langsung (HOK) & $(4)=(1) /(2)$ \\
4 & Faktor Konversi & $(5)=(3) /(2)$ \\
5 & Koefisien Tenaga Kerja Langsung (HOK/Kg) & $(6)$ \\
6 & Harga Output (Rp/Kg) & $(7)$ \\
7 & Upah Tenaga Kerja langsung (Rp/HOK) & $(8)$ \\
\hline 2$)$ & Penerimaan dan Keuntungan & $(9 \mathrm{a})$ \\
\hline 8 & Harga Bahan Baku (Rp/Kg) & $(9 \mathrm{~b})$ \\
9 & a.Sumbangan Input Lain Rasa Pandan & $(10)=(4) \times(6)$ \\
& a. Sumbangan Input Lain Rasa Durian & $(11 \mathrm{a})=(10)-(8)-(9)$ \\
10 & Nilai Output (Rp/Kg) & $(11 \mathrm{~b})=(11 \mathrm{a}) /(10) \times 100$ \\
11 & a. Nilai Tambah (Rp/Kg) & $(12 \mathrm{a})=(5) \times(7)$ \\
& b. Rasio nilai tambah (\%) & $(12 \mathrm{~b})=(12 \mathrm{a}) /(11 \mathrm{a}) \times 100$ \\
12 & a. Pendapatan tenaga kerja langsung $(\mathrm{Rp} / \mathrm{Kg})$ & $(13 \mathrm{a})=(11 \mathrm{a})-(12 \mathrm{a})$ \\
& b. Pangsa Tenaga Kerja $(\%)$ & $(13 \mathrm{~b})=(13 \mathrm{a}) /(10) \times 100$ \\
13 & a. Keuntungan $(\mathrm{Rp} / \mathrm{Kg})$ & \\
& b. Tingkat Keuntungan $(\%)$ & \\
\hline
\end{tabular}

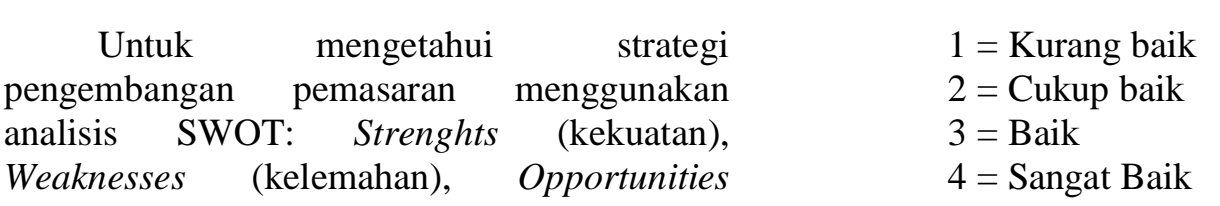

(peluang), Threats (ancaman). Menurut David

(2006), skala nilai rating untuk matriks IFE

(kekuatan dan kelemahan) adalah:

Tabel 2. Matriks Internal Factor Evaluation (IFE)

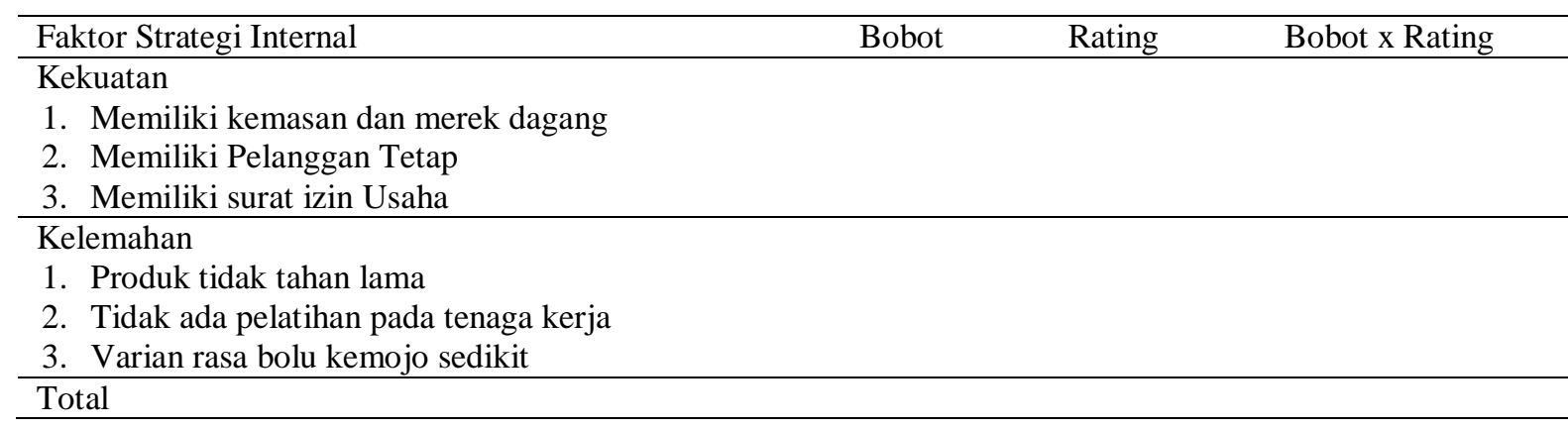

Tabel 3. Matriks Eksternal Factor Evaluation (EFE)

\begin{tabular}{|c|c|c|}
\hline Faktor Strategi Eksternal & Rating & Bobot $\mathrm{x}$ Rating \\
\hline $\begin{array}{l}\text { Peluang } \\
\text { 1. Produk dikenal sebagai oleh-oleh khas Melayu } \\
\text { 2. Perkembangan teknologi promosi } \\
\text { 3. Adanya event pameran }\end{array}$ & & \\
\hline $\begin{array}{l}\text { Ancaman } \\
\text { 1. Pesaing produk sejenis sangat banyak } \\
\text { 2. Kenaikan harga bahan baku dan bahan } \\
\text { penunjang } \\
\text { 3. Daya beli masyarakat yang menurun }\end{array}$ & & \\
\hline
\end{tabular}

Menurut David (2006), skala nilai rating untuk matriks EFE (peluang dan kekuatan) adalah: $1=$ Kurang baik
2 = Cukup baik

$3=$ Baik

$4=$ Sangat baik 
Adapun ketentuan pembulatan dalam matriks gabungan ini adalah, jika pecahan decimal berada pada kisaran dibawah $0,5 \quad(<0,5)$ dibulatkan ke bawah, jika hasil rating diperoleh hasil decimal dengan nilai sama atau $\mathrm{di}$ atas 0,5 (>0,5) dibulatkan ke atas. Pembulatan ini tentunya tidak akan mempengaruhi hasil perhitungan secara signifikan (David, 2006).

\section{HASIL DAN PEMBAHASAN}

\section{Profil Usaha Agroindustri Bolu Kemojo}

Keberhasilan pengusaha dalam mengelola usahnya di pengaruhi oleh beberapa faktor meliputi: umur, pendidikan, jumlah tanggungan keluarga dan pengalaman usaha. umur pelaku usaha bolu kemojo Cik Puan berada pada usia produktif yaitu 49 tahun sehingga dalam menjalankan usahanya pengusaha mampu mengolah usahanya dengan baik sedangkan umur tenaga kerja yaitu ratarata umur 23 tahun, pendidikan pengusaha bolu kemojo Cik Puan selama 12 tahun sedangkan tingkat pendidikan tenaga kerja rata-rata selama 12 tahun, jumlah tanggungan keluarga pengusaha Cik Puan sebanyak 3 jiwa yaitu 1 orang istri dan 2 orang anak sedangkan tenaga kerja tidak memiliki tanggungan keluarga, pengalaman usaha Cik Puan selama 13 tahun sedangkan pengalaman usaha tenaga kerja rat-rata 4,5 tahun.

Usaha industri Cik Puan di Kelurahan Tangkerang Selatan Kecamatan Bukit Raya Kota Pekanbaru ini dimulai sejak tahun 2007 hingga sekarang.sumber modal yang digunakan pengusaha Cik Puan yaitu berasal dari pinjaman bank. modal yang dikeluarkan oleh usaha Cik Puan sebanyak Rp 120.000.000.00, diantaranya $\mathrm{Rp}$ 65.000.000.00 untuk sewa bangunan selama 1 tahun.

Usaha industri adalah suatu unit yang melakukan kegiatan ekonomi yang bertujuan untuk menghasilkan barang dan jasa, terletak pada suatu lokasi tertentu dan memiliki catatan administrasi tersendiri mengenai produk dan struktur biaya serta seseorang yang bertanggung jawab atas usaha yang dijalankan.Dari hasil pengamatan dilapangan menunjukkan bahwa usaha cik puan masih berskala kecil/rumah tangga yang masih menggunakan 2 orang tenaga kerja dari luar keluarga. Pemilik usaha agroindustri bolu kemojo cik puan mempunyai wewenang untuk melakukan seluruh kegiatan usaha mulai dari merencanakan strategi, mengambil keputusan, menjalankan usaha, menetapkan suatu kebijakan, proses produksi sampai dengan pengolahan keuntungan yang dihasilkan dari usahanya dan bertanggung jawa terhadap kelangsungan hidup usaha yang dijalankan.

Bahan baku merupakan salah satu faktor utama dalam proses produksi agroindustri, salah satunya adalah agroindustri bolu kemojo menggunakan bahan baku tepung terigu. Bahan penunjang merupakan bahan tambahan yang akan diperlukan dalam proses produksi, untuk memperoleh bahan penunjang dilihat dari ketersediaan yang relatif bermanfaat.

Proses produksi bolu kemojo adalah serangkaian kegiatan yang dilakukan oleh pengusaha bolu kemojo mulai dari penyiapan bahan hingga produk siap di jual. Selama 240 menit (satu kali proses produksi $5 \mathrm{~kg}$ bahan baku).

Tenaga kerja sebagai salah satu faktor produksi yang akan menentukan proses produksi dan peningkatan pendapatan usaha agroindustri, karena tenaga kerja merupakan pelaku utama dalam proses produksi. Tenaga kerja yang tidak sesuai dengan situasi usaha akan menyebabkan kerugian pada usaha agroindustri , karena tenaga kerja sebagai faktor produksi yang harus diperhitungkan secara benar. Tenaga kerja yang digunakan dalam proses agroindustri bolu kemojo adalah tenaga kerja luar keluarga.

\section{Analisis Usaha}

Biaya produksi pada usaha agroindustri bolu kemojo terdiri dari biaya sarana produksi seperti biaya bahan baku dan bahan penunjang, biaya penyusutan dan biaya bangunan yang digunakan dalam proses produksi. Adapun biaya-biaya yang dimaksud dalam penelitian ini adalah seluruh biaya yang dikeluarkan dalam proses produksi bolu kemojo.

Pada Tabel 4, menunjukkan bahwa bahan baku tepung terigu yang digunakan dengan jumlah $5 \mathrm{~kg} /$ proses produksi maka akan mengasilkan output sebanyak $24 \mathrm{~kg}$ bolu kemojo per proses diantaranya $12 \mathrm{~kg}$ rasa pandan dan $12 \mathrm{~kg}$ rasa durian dengan harga jual Rp 42.500/kg. Kotak kemasan kecil isi satu pcs bolu kemojo dengan berat 400gr, sedangkan kotak kemasan besar isi dua pcs bolu kemojo dengan berat 800gr. Hasil pendapatan kotor dan pendapatan bersih dapat dilihat pada Tabel 16. Pendapatan kotor yang diterima pengusaha bolu kemojo sebesar Rp. 
1.020.000,00/proses produksi diantaranya rasa pandan sebesar Rp 510.000/proses produksi, rasa durian sebesar $\mathrm{Rp}$ 510.000/proses produksi sedangkan pendapatan bersih sebesar Rp. 700.980/proses produksi.

Return Cost of Ratio (RCR), yaitu membandingkan antara pendapatan kotor dengan biaya produksi. Pada Tabel 16 dapat diketahui efisiensi usaha agroindustri bolu kemojo sebesar 2,20. Berarti setiap mengeluarkan $\mathrm{Rp} 2$ akan mendapatkan pendapatan kotor sebesar $\mathrm{Rp} \quad 2,20$ dan pendapatan bersih sebesar $\mathrm{Rp} 1,20$, dari nilai RCR ini kegiatan agroindustri bolu kemojo layak dilanjutkan karena dapat memberikan imbalan berupa keuntungan.

Tabel 4. Analisis Biaya, Pendapatan, dan Efisiensi per Proses pada Usaha Agrindustri Bolu Kemojo Cik Puan di Kelurahan Tangkerang Selatan, Tahun 2020.

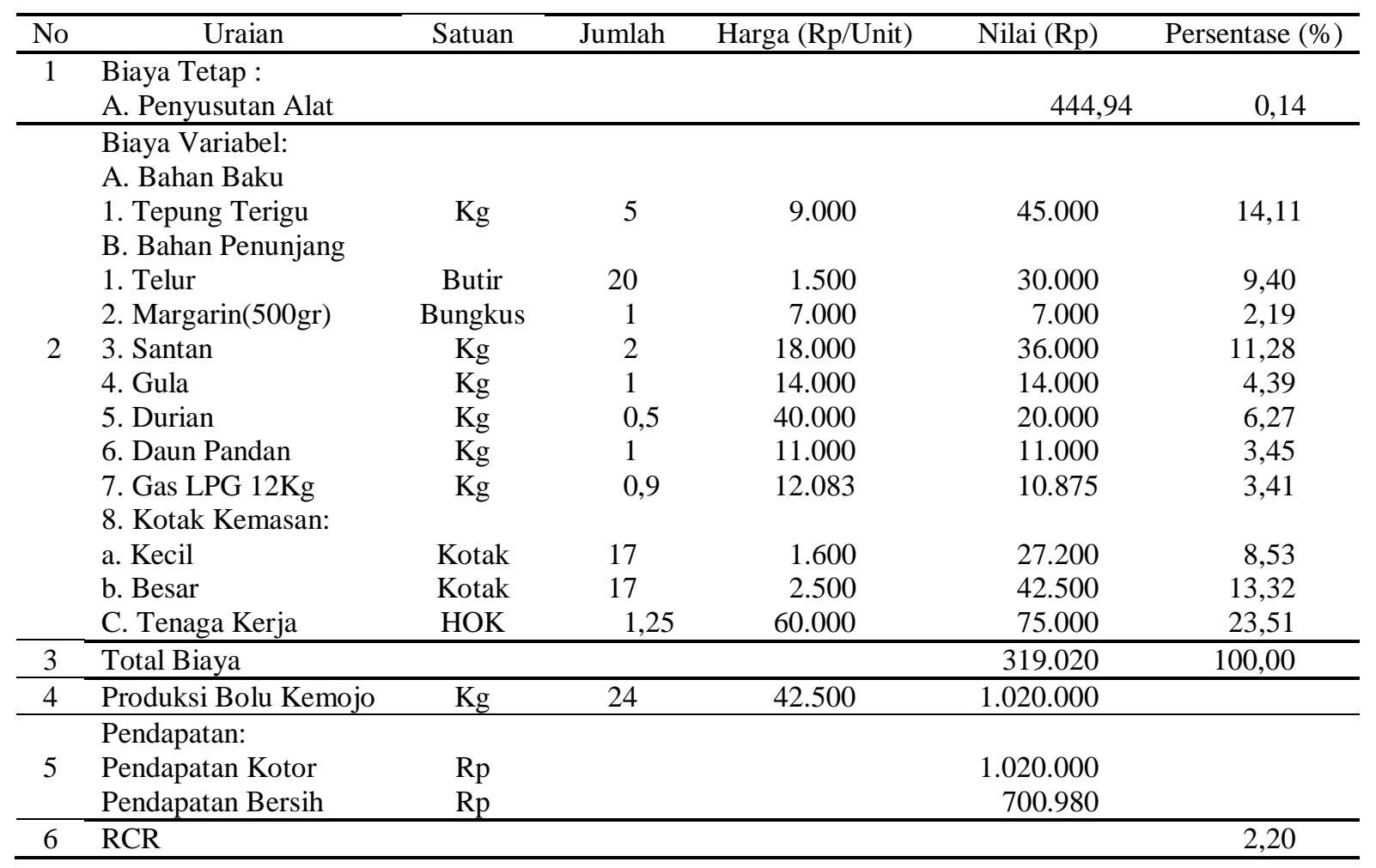

Salah satu tujuan pegolahan hasil produk pertanian adalah menghasilkan nilai tambah. Nilai tambah yang akanditerima merupakan pendapatan dan keuntungan pengusaha agroindustri bolu kemojo dan balas jasa pemilik faktor produksi. Analisis nilai tambah merupakan metode perkiraan bahan baku yang akan mendapatkan perlakuan khusus untuk memperoleh nilai tambah. Perhitungan nilai tambah produksi bolu kemojo pada usaha cik puan dilakukan dengan metode nilai tambahn Hayami, et all (2001). Pada Tabel 5 nilai tambah agroindustri bolu kemojo cik puan menghasilkan output sebanyak $24 \mathrm{Kg}$ /proses produksi diantaranya $12 \mathrm{Kg}$ rasa pandan dan $12 \mathrm{Kg}$ rasa durian, dengan input yang digunakan adalah $5 \mathrm{Kg} /$ proses produksi. Harga bahan baku tepung Rp $9.000 / \mathrm{Kg}$, sumbangan input lain rasa pandan $\mathrm{Rp} 11.000 / \mathrm{kg}$ dan sumbangan input lain rasa durian $\mathrm{Rp}$ 40.000/kg. Harga ouput bolu kemojo Rp $42,500 / \mathrm{kg}$. Nilai output bolu kemojo yang dihasilankan dari faktor konversi dikali dengan harga output sebesar Rp 204.000/kg. Nilai tambah yang diperoleh dari tepung menjadi bolu kemojo adalah sebesar Rp 149.500/kg. Rasio nilai tambah bolu kemojo sebesar $73,28 \%$. Pendapatan tenaga kerja diperoleh dari koefisien tenaga kerja yang dikali dengan upah tenaga kerja adalah sebesar Rp $15.000 / \mathrm{kg}$. Pangsa tenaga kerja yang diperoleh adalah $10,03 \%$, pangsa tenaga kerja adalah menunjukkan persentase tenaga kerja dari nilai tambah. Keuntungan nilai tambah yaitu sebesar Rp 134.500 dan tingkat keuntungan yang diperoleh sebesar 65,93\%. 
Analisis Usaha dan Strategi Pengembangan Pemasaran Bolu Kemojo di Kelurahan Tangkerang Selatan Kecamatan Bukit Raya Kota Pekanbaru (Studi Kasus pada Usaha Cik Puan)

Tabel 5. Analisis Nilai Tambah pada Usaha Agroindustri Bolu Kemojo Cik Puan per Proses Produksi di Kelurahan Tangkerang Selatan, Tahun 2020.

\begin{tabular}{clrr}
\hline No & \multicolumn{1}{c}{ Variabel } & Satuan & Nilai \\
\hline 1$)$ & Output, Input dan Harga & $\mathrm{Kg}$ & 24,00 \\
\hline 1 & Output : (1) & $\mathrm{Kg}$ & 5,00 \\
2 & Input : (2) & $\mathrm{HOK}$ & 1,25 \\
3 & Tenaga Kerja Langsung : (3) & & 5,00 \\
4 & Faktor Konversi : (1)/(2) & $\mathrm{HOK} / \mathrm{Kg}$ & 0,25 \\
5 & Koefisien Tenaga Kerja Langsung : (5)=(3)/(2) & $\mathrm{Rp} / \mathrm{Kg}$ & $42.500,00$ \\
6 & Harga Output : (6) & $\mathrm{Rp} / \mathrm{HOK}$ & $60.000,00$ \\
7 & Upah Tenaga Kerja langsung : (7) & & \\
\hline 2$)$ & Penerimaan dan Keuntungan & $\mathrm{Rp} / \mathrm{Kg}$ & $9.000,00$ \\
\hline 8 & Harga Bahan Baku : (8) & $\mathrm{Rp} / \mathrm{Kg}$ & $11.000,00$ \\
9 & a. Sumbangan Input Lain Rasa Pandan: $(9 \mathrm{a})$ & $40.000,00$ \\
& b. Sumbangan Input Lain Rasa Durian: $(9 \mathrm{~b})$ & $\mathrm{Rp} / \mathrm{Kg}$ & $204.000,00$ \\
10 & Nilai Output : (10)= (4) x (6) & $\mathrm{Rp} / \mathrm{Kg}$ & $149.500,00$ \\
11 & a. Nilai Tambah : (11a)= (10) - (8) - (9) & $\%$ & 73,28 \\
& b. Rasio nilai tambah : (11b)= (11a)/(10) x 100\% & $\mathrm{Rp} / \mathrm{Kg}$ & $15.000,00$ \\
12 & a. Pendapatan tenaga kerja langsung : (12a)=(5)x(7) & $\%$ & 10,03 \\
& b. Pangsa Tenaga Kerja : (12b)=(12a)/(11a) x100\% & $\mathrm{Rp} / \mathrm{Kg}$ & $134.500,00$ \\
13 & a. Keuntungan : (13a)= (11a) - (12a) & $\%$ & 65,93 \\
\hline
\end{tabular}

\section{Analisis SWOT}

Berdasarkan hasil pembobotan masingmasih faktor, dapat disusun matriks SWOT untuk melihat keterkaitan masing-masing faktor tersebut dan merumuskannya menjadi strategi pemasaran agroindustri bolu kemojo cik puan di Kelurahan Tangkerang Selatan Kecamatan Bukit Rata Kota Pekanbaru. Analisis keterkaitan antara faktor menghasilkan beberapa strategi pengembangan pemasaran pada agroindustri bolu kemojo seperti pada Tabel 6 .

Tabel 6. Matriks SWOT pada Usaha Agroindustri Bolu Kemojo Cik Puan di Kelurahan Tangkerang Selatan, Tahun 2020.

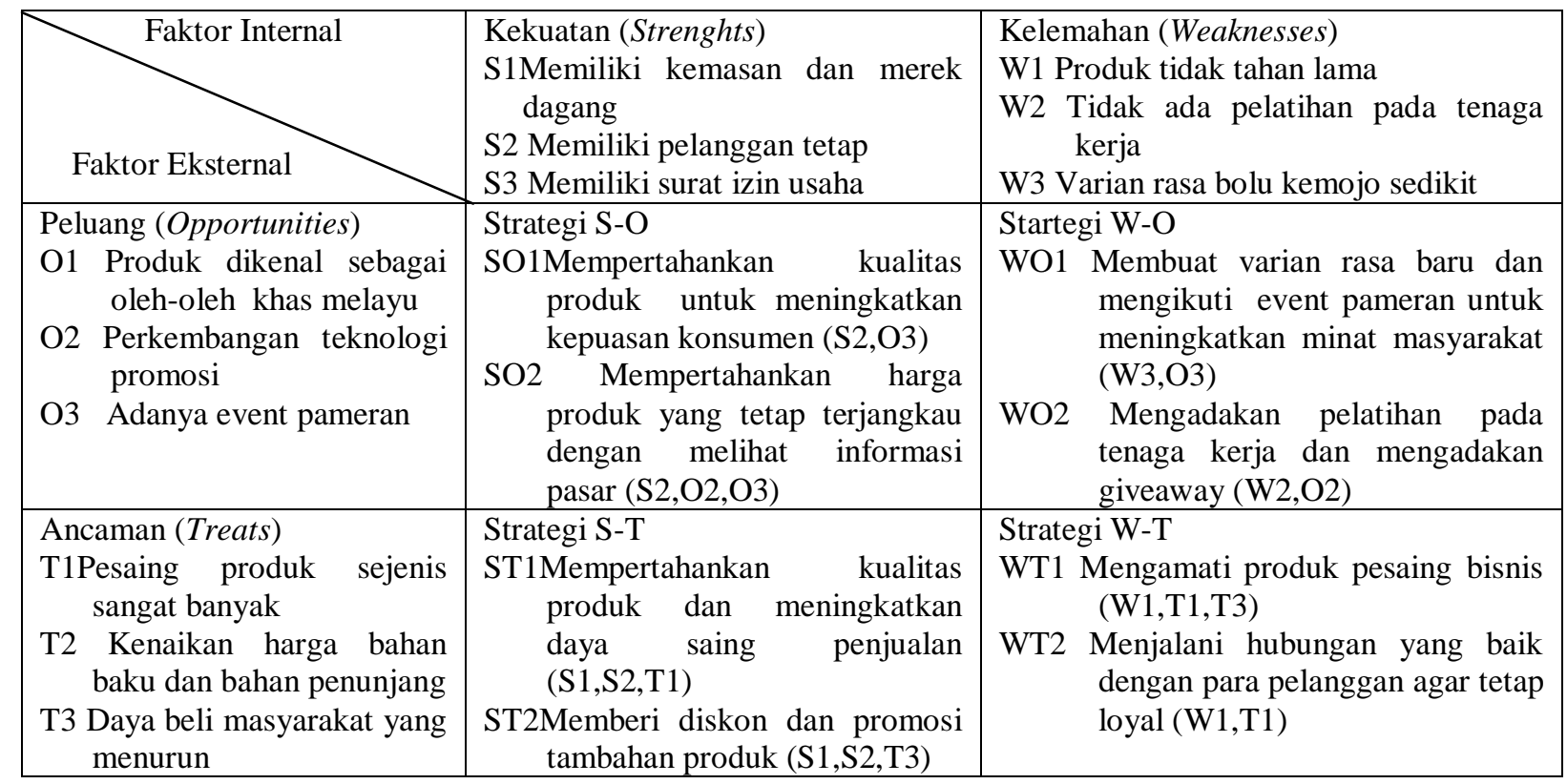

\section{KESIMPULAN DAN SARAN}

Kesimpulan
1. Karakteristik pengusaha menunjukkan bahwa pemilik usaha Cik Puan berada pada umur yang produktif yaitu 49 tahun, sedangkan umur tenaga kerja rata-rata 23 
tahun, lama pendidikan pengusaha yaitu 12 tahun, sedangkan pendidikan tenaga kerja rata-rata 12 tahun, jumlah tanggungan keluarga pengusaha yaitu 3 orang, sedangkan jumlah tanggungan keluarga tenaga kerja tidak ada yang ditanggungkan dan pengalaman usaha pengusaha selama 13 tahun, sedangkan pengalaman usaha tenaga kerja rata-rata 4,5 tahun. Profil usaha Cik Puan berdiri tahun 2007 sampai saat ini, modal berasal dari pinjaman bank, skala usaha yang digunakan yaitu skala rumah tangga yang menggunakan tenaga kerja 2 orang.

2. Penggunaan bahan baku tepung terigu sebesar $5 \mathrm{Kg}$ /proses produksi dengan harga Rp 9.000/Kg, penggunaan bahan penunjang dengan jumlah Rp 198.575/proses produksi. Teknologi yang digunakan masih tergolong sederhana yaitu dengan alat-alat yang masih membutuhkan tenaga kerja manusia, mulai dari penyedian bahan-bahan hingga proses akhir. Total biaya sebesar Rp 319.020, Pendapatan kotor Rp 1.020.000/proses produksi dan pendapatan bersih $\mathrm{Rp}$ 700.980/proses produksi, Return Cost Ratio (RCR) yang di peroleh sebesar 2,20, nilai tambah yang diperoleh sebesar $\mathrm{Rp}$ $149.500 / \mathrm{kg}$.

3. Strategi berdasarkan analisis SWOT ditunjukkan untuk mengidentifikasi berbagai faktor untuk merumuskan strategi berdasarkan faktor-faktir internal dan faktor-faktor eksternal diperoleh skor pembobotan sebagai berikut: faktor kekuatan $=2,77$; faktor kelemahan $=0,56$; faktor peluang $=2,59$; faktor ancaman $=$ 0,47 . Hasil analisis pada matriks SWOT diperoleh koordinat $(2,49 ; 2,35)$ yang mana koordinat ini terletak pada kuadran I yaitu SO: Mempertahankan kualitas produk untuk meningkatkan kepuasan konsumen dan mempertahankan harga produk yang tetap terjangkau dengan melihat informasi pasar.

\section{Saran}

1. Kepada pengusaha: perlu meningkatkan kualitas produk dari segi bentuk, tekstur, dan rasa, agar produk yang ditawarkan menarik sehingga konsumen tertarik untuk membeli produk bolu kemojo dan bisa mendapat keuntungan lebih. Hal ini dilakukan sebagai antisipasi apabila ada kesamaan produk pada usaha lain.
2. Kepada pemerintah: diharapkan dapat memberikan bantuan dan membuat pameran agar makanan ciri khas melayu makin banyak dikenal dan semakin banyak diminati.

3. Kepada akademisi: agar dapat meneliti lebih lanjut mengenai bagaimana strategi peningkatan pendapatan pengusaha bolu kemojo dalam pemasarannya.

\section{DAFTAR PUSTAKA}

David, R. F. 2006. Manajemen Strategi: Konsep. Edisis Kesepuluh. Salemba Empat, Jakarta

Hernanto, F. 1993. Ilmu Usahatani. Penebar Swadaya, Jakarta.

Soekartawi. 1995. Prinsip Dasar Ekonomi Pertanian Teori dan Aplikasinya. Raja Grafindo Persada, Jakarta.

Soekartawi. 2001. Pengantar Agroindustri, Edisi Pertama. PT Raja Grafindo Persada, Jakarta.

Soekartawi. 2002. Analisis Usahatani. Universitas Indonesia, Jakarta.

Yasin, A. Z. F dan M. Ahmad. 1996. Usaha Kecil Kelembagaan dan Agribisnis. UNRI Press, Pekanbaru. 